\title{
Extensive intracranial lesions in a case of orbital non-specific granuloma combined with polyarteritis nodosa
}

\author{
K. E. ÅSTRÖM AND S. O. LIDHOLM \\ From the Department of Pathology II, Karolinska Institute, \\ Sabbatsbergs Hospital, Stockholm, Sweden
}

SYNOPSIS A unique case of a non-specific orbital granuloma in a 65-year-old woman is described. Necropsy disclosed extensive spread of the granuloma to the pachy- and leptomeninges as well as elsewhere. There were also signs of generalized polyarteritis nodosa. For five years the patient had severe facial pain and for four years signs of impaired renal function. A psychosis developed two months before her death. Previously she had had infections in the upper respiratory pathways and bilateral episcleritis. The nosology, aetiology, and pathogenesis of the condition are discussed.

The orbits, nose, and sinuses may be the site not only of true tumours but also of space-occupying lesions of a granulomatous type. Many cases have a well-known aetiology: the basic disease can be tuberculosis, syphilis, mycosis, malignant lymphoma, etc. However, some of the lesions seem to belong to special groups, which are known under various names. The nasal granuloma has been called malignant or lethal granuloma or idiopathic lethal granulomatous ulceration in the midline-structure of the face (see, e.g., Stewart, 1933; Friedmann, 1955; Hultberg, Koch, Moberger, and Mårtensson, 1957). The orbital lesions are sometimes called pseudotumours of the orbit (Reese, 1956).

The aetiology of these cases is unknown and their classification is a matter of conjecture. These conditions are not common. Therefore, in order to increase our knowledge it seems advisable to report all the cases where the clinical history was well known and a complete post-mortem examination was carried out. The present report is of a case that fulfils these requirements. Moreover, it has an added interest, since it exhibited some unusual features: the granulomatous lesion involved several cranial nerves both inside and outside the cranial cavity, and also had spread extensively to the pachy- and leptomeninges.

\section{CASE HISTORY}

A 65-year-old woman (Sabbatsbergs Hospital, Medical

Received for publication 14 August 1962
Service 247/60) had a nasal obstruction for about six months and an acute infection in the right middle ear during 1952. Staphylococci were cultivated from nasal excretions and biopsy showed a non-specific inflammatory process. Bilateral episcleritis appeared in 1953; it subsided in the right eye but persisted in the left. From 1955 onwards the dominant symptom was severe pain in the left side of the face. Migrating pains in the joints and signs of impaired renal function occurred in 1956. The left eye, which was then phthisic, was removed in 1959 and a non-specific chronic granuloma was found in the orbit. In January 1960, her blood pressure was $220 / 110 \mathrm{~mm}$. $\mathrm{Hg}$ (in 1956 it had been $120 / 80 \mathrm{~mm}$. $\mathrm{Hg}$ ), the creatinine clearance $16 \mathrm{ml} . / \mathrm{min}$., and the sedimentation rate $60 \mathrm{~mm}$. Cultivation of secretions from the orbit showed, on different occasions, growth of diphtheroid organisms and anaerobic gamma-streptococci. A severe mental change took place finally and the patient died in a mental hospital in July 1960.

\section{POST-MORTEM EXAMINATION}

The body was that of a small but not particularly emaciated woman.

A $5 \mathrm{~mm}$. thick layer of greyish tissue was firmly attached to the falx and the inside of the dura over both hemispheres (Fig. 1). Similar tissue was found on the bases of both the anterior cranial fossae, the left middle fossa, in the cavernous sinus, the chiasmatic sulcus, around both optic fascicles at the optic foramina, and around the pituitary body, the Gasserian ganglion, carotid siphon, ocular muscle nerves, and the second and third branches of the 
trigeminus at the foramen rotundum and foramen ovale on the left side. Furthermore, granulation tissue filled the superior and inferior orbital fissures, the left orbit, and the upper part of the left pterygopalatine fossa. The frontal, maxillary, sphenoid sinuses, ethmoid cells, epipharynx and nasal cavities, and the mucous membranes were unaffected.

Yellow-green material had accumulated around the blood vessels in the sulci of the fronto-parietal regions (Fig. 1). The arteries of the brain were patent. Coronal sections showed a small laminar necrosis in the cortex of the right frontal lobe and an old malacia in the right occipital lobe.

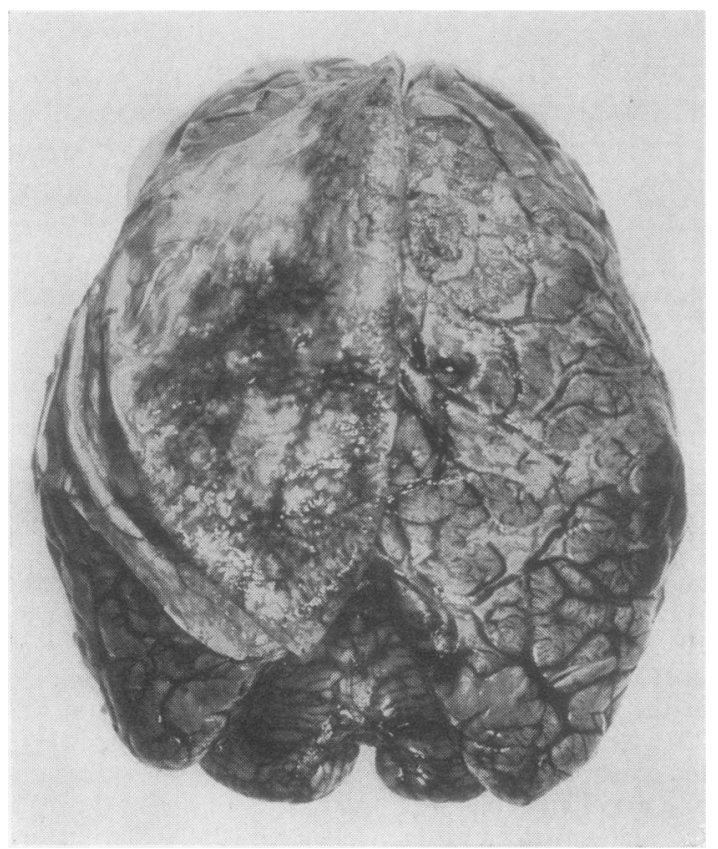

FIG. 1. Dorsal view of the brain showing granulation tissue in the subarachnoid space of the right hemisphere and on the inner aspect of the reduplicated dura.

The pericardial membranes adhered to each other, the heart appeared normal, and there was little atherosclerosis. The right pulmonary artery was occluded at the hilus by a fresh thrombus. There were no gross lesions within the lungs. The spleen was firm. The kidneys were rather small and pale, their surfaces pitted, and the cortices narrowed.

GRANULATION TISSUE IN THE ORBIT AND ADJACENT REGIONS This hyaline, fibrotic mass contained areas of necrosis, partly of a fibrinoid type and many inflammatory cells, mostly lymphocytes and monocytes, a moderate number of epithelioid cells, and

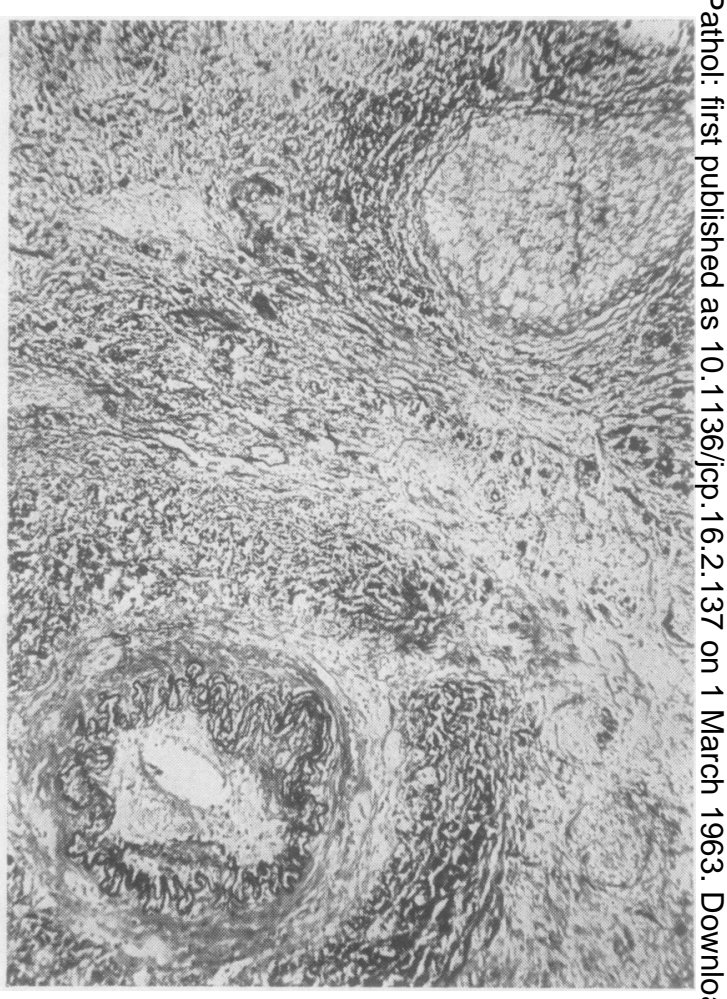

FIG. 2. Granulation tissue from left orbit. Small artery with recanalized thrombus and nerve branch are included in the fibrotic mass. Haematoxylin, eosin, and elastin. $\times 30 . \overrightarrow{\overrightarrow{0}}$

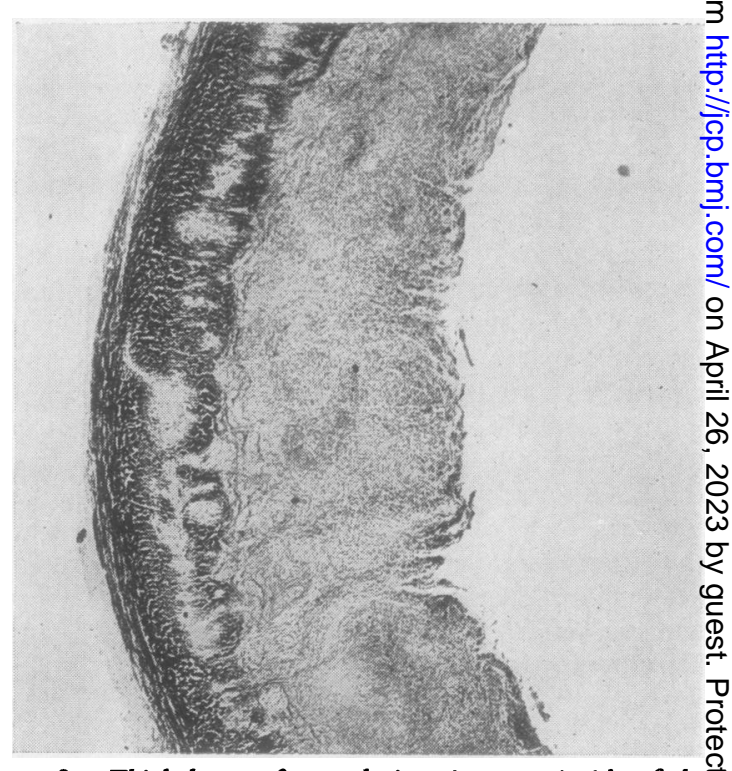

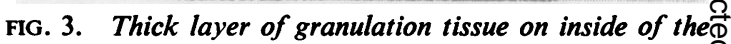
dura, thin layer on outside and small patches of destruction within the dura itself. Haematoxylin and eosin $\times 15$. 


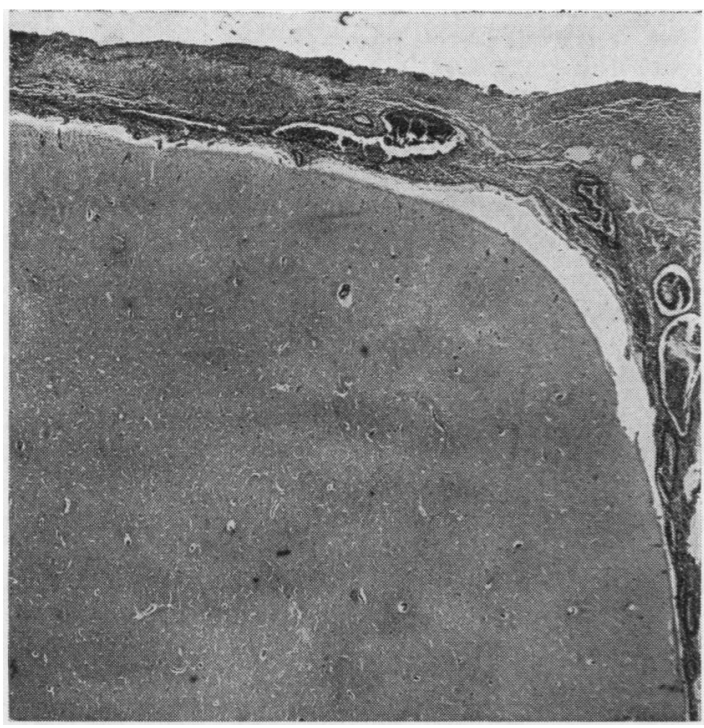

FIG. 4. Granulation tissue in subarachnoid space. No gross lesions in cortex here. Haematoxylin and eosin $\times 50$.

some giant cells. The walls of several blood vessels showed a diffuse infiltration with inflammatory cells, fibroblastic thickening of the intima, and splitting of the internal elastic membrane (Fig. 2). Some vessels appeared to have been occluded, and subsequently, recanalized; others remained as solid cords of connective tissue. The left orbit also contained an atrophic optic fascicle, atrophic nerves without inflammation (Fig. 2), and remnants of muscle fibres separated by inflammatory cells.

There was a thick layer of granulation tissue on the inside of the dura, a thin layer on the outside, and small patches of destruction and granulation tissue within the dura itself (Fig. 3).

The leptomeninges showed a patchy thickening with proliferation of collagenous fibrils, collections of round cells, macrophages, fibroblasts, epithelioid cells, and occasional giant cells, and a few inflamed arteries and areas of necrosis were also noted (Fig. 4).

The leptomeninges either adhered to each other or were separated by fibrinous and partly necrotic masses.

An old laminar necrosis was observed in the deep layers of the cortex of the right frontal lobe of the brain. Destruction of single nerve cells and ischaemic changes were occasionally seen elsewhere in the cortex. There was a moderate proliferation of microglial cells and astrocytes, especially in the subpial regions.

The basal ganglia, putamen, pallidum, thalamus, brain-stem, and cerebellum were normal.
OTHER ORGANS The epicardial membrane was split into several layers and infiltrated by round cells, some epithelioid cells and rare giant cells of the foreign body type. A few round cells were scattered in the myocardium.

Small scattered areas of recent bronchopneumonia were found in the lungs.

There was considerable arterio- and arteriolosclerosis in the kidneys. Many arteries were inflamed and some had been thrombosed and recanalized. Approximately half or more of the glomeruli had become hyalinized; some contained epithelioid cells and others displayed signs of fibrinoid degeneration. A few capillary tufts were occluded by thrombi of

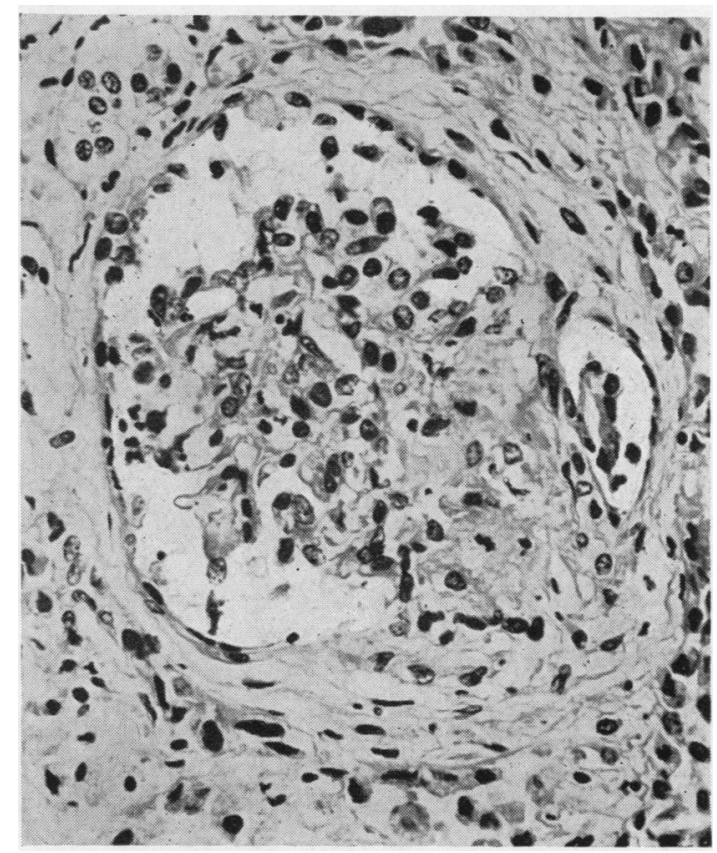

FIG. 5. Kidney glomerulus with focal capillary necrosis, exudation of fibrin, and a few inflammatory cells. Haemato$x y$ lin and eosin $\times 400$.

fibrin. A few intracapsular leucocytes were seen and occasional crescent formations were also noted (Fig. 5). These severe changes in the kidney resembled those in acute and subacute or subchronic glomerulonephritis; the inflammation in the arteries was a striking and unusual feature.

Many vessel walls in small and medium-sized arteries of the spleen exhibited necrosis of a fibrinoid type and inflammation (Fig. 6).

Sections from the liver, adrenals, pancreas, bone marrow, aorta, and skeletal muscles showed no abnormality. 


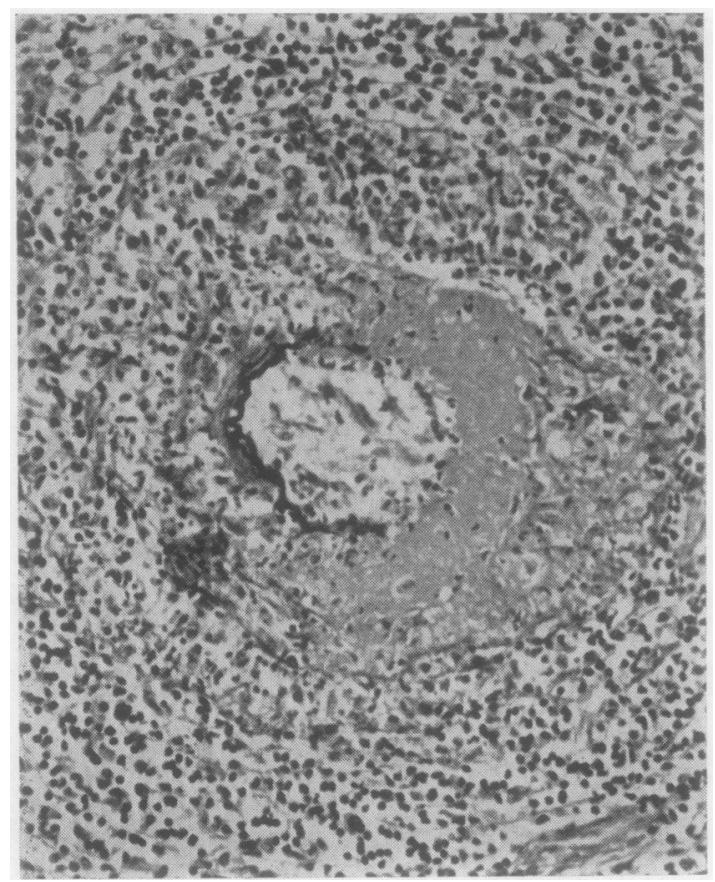

FIG. 6. Fibrinoid degeneration in segment of a small artery in the spleen. Haematoxylin and eosin $\times 200$.

MICROORGANISMS No microorganisms were seen in sections from the orbital granulation tissue, dura and leptomeninges, which were specially stained for bacteria, tubercle bacilli, and fungi.

\section{DISCUSSION}

DIAGNOSIS Chronic inflammatory granulomata are prominent among those lesions which simulate true tumours in the orbital cavity (Duke-Elder, 1952; Reese, 1956). After the exclusion of cases where the aetiology is known, such as tuberculosis and syphilis, there is still a group where the responsible agent cannot be identified, and presumably, is not bacterial. The present case seems to belong to that group, since culture of discharges from the left orbit and the nasal mucous membranes never showed any consistent findings of bacterial growth, the Wassermann reaction was negative, and any existing microorganisms could not be demonstrated in appropriately stained sections from the necropsy material. On the other hand, certain histological features, such as fibrinoid necrosis and vasculitis, were more in line with an immunological disturbance (cf. Easton and Smith, 1961) than with an infectious process.

The lesions in the other organs of this case, such as arteritis of different ages in the spleen and kidneys, and glomerulonephritis, could best be interpreted as signs of a generalized polyarteritis nodosa.

RELATIONSHIP BETWEEN ORBITAL GRANULOMA AND OTHER CONDITIONS Although chronic non-bacterial orbital granuloma can exist as a disease sui generis $\frac{\bar{c}}{\bar{c}}$. there is evidently in some cases a relation to other $\overrightarrow{\mathbb{D}}$ conditions. Thus, several features suggest a kinship $\varrho$ to malignant granuloma of the nose: frequently is their histological pictures are similar (Howells, 1955; $\overrightarrow{0}$ Friedmann, 1955); the lesions appear to be the result $\overrightarrow{-}$ of a non-specific reaction to an unknown agent; $\vec{\omega}$ presumably the aetiology is allergic (Williams, 1949); both conditions can be associated with polyarteritis? nodosa and Wegener's granulomatosis. A more $\vec{\sigma}$ direct relationship exists between nasal and orbital granulomata in those cases where the process $\vec{\omega}$ started in the nose and subsequently involved ${ }_{0}$

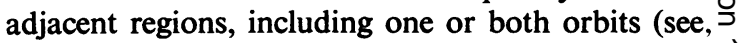
for instance, Alexander's case 2,1954$)$. It has also $\vec{z}$ been suggested that, even if a lesion is confined to the orbital cavity, the disease can still have originated $\widehat{\widehat{S}}$ in the sinuses (Jackson, 1958). The present case $\vec{\oplus}$ supports this hypothesis. Admittedly, the post- $\mathscr{\odot}$ mortem examination showed lesions only in the orbital cavity; the nose and sinuses were unaffected. However, the patient had suffered from inflammation and infection in the nose, sinuses, and ears during ano extended period some time before the ocularő symptoms appeared. Therefore, it is conceivable that $\stackrel{\mathbb{Q}}{2}$ the disease started in the nasal regions and sub- $\overrightarrow{0}$ sequently spread to the orbit while the original 3 process healed.

Wegener's granulomatosis, although forming a well-defined syndrome (Godman and Churg, 1954), is also related to the entities under discussion here. Its kinship to malignant granuloma of the nose is 3 well known; the disease is sometimes dominated by symptoms from the nasal and paranasal regions (Woodburn and Harris, 1951; Ahlström, Liedholm, and Truedsson, case 2, 1953; Howells, case 1, 1955)? and Wegener himself coined the phrase 'rhinogenes Granulomatose' in his classical paper (1939). It is also known, that orbital granuloma can occur in cases of Wegener's syndrome (Faulds and Wear, $N$ 1960; see also Straatsma's survey, 1957). Our case could not be classified as Wegener's granulomatosis since no lesions were found in the respiratory organs? at necropsy. Nevertheless, a relationship is highlye probable for the following reasons: initially the patient had symptoms in the nose, maxillary sinuses and ears and nasal biopsies then showed granulo- $\frac{0}{0}$ matous lesions; presumably orbital granuloma can $\overrightarrow{0}$ originate in the nasal and paranasal regions (vide $\stackrel{\stackrel{\mathrm{O}}{\mathrm{Q}}}{\mathrm{O}}$ supra).

These granulomatous diseases may in some waye 
be connected with polyarteritis nodosa. The association of Wegener's syndrome with this arterial disease is well known; like Wegener himself many authors, e.g., Ringertz (1947), have regarded this syndrome as a peculiar form of polyarteritis nodosa. Others, however, have considered the syndrome to be a combination of nasal or pulmonary granuloma and polyarteritis nodosa (e.g., Weinberg, 1946; Stratton, Price, and Skelton, 1953; Howells, 1955).

The coexistence of orbital granuloma and polyarteritis nodosa, as seen in the present case and in three similar cases (see Table), shows that these conditions can also be causally related. The observations of Alexander (1954), Howells (1955), Paterson (1956), Jackson (1958), and Flatmark (1961) point in the same direction.

The relation of granulomatous processes to polyarteritis nodosa has been elucidated, especially by Rose and Spencer (1957). On the basis of 111 cases, two types of polyarteritis nodosa were distinguished, these possibly but not certainly representing variants of the same condition. One type comprised cases of the common type, which lack granulomatous lesions. The outstanding features of the other type were early respiratory symptoms, and the presence of granulomatous necrotizing lesions, above all in the lungs but also in the nasal and middle ear regions or elsewhere in the body. Both Wegener's granulomatosis and other 'syndromes' similar to that observed in the present case might be included in this second group.

In conclusion, our case, as well as a survey of the literature, emphasizes that the relationship may exist between non-specific orbital and nasal granulomata and Wegener's granulomatosis on the one hand, and between these conditions and polyarteritis nodosa, on the other.

PATHOGENESIS AND AETIOlOGY Rose and Spencer (1957) have presented convincing evidence that abnormal immune reactions to respiratory infections may be the basis for polyarteritis nodosa. Accordingly, it is a case in point that sinusitis is often present initially in both malignant granuloma of the nose and in Wegener's granulomatosis (Howells and Friedmann, 1950; Godman and Churg, 1954; Friedmann, 1955). In our case of orbital granuloma there were symptoms of infection in the nose, sinuses, and ear before the appearance of eye symptoms. Similarly, inflammation in the paranasal cavities occurred early in two other cases shown in the Table, namely, in the ethmoidal and sphenoidal cells in Walton's case, and in a maxillary sinus in that of Faulds and Wear. Thus, upper respiratory infections seem to be a pathogenic factor in certain cases of granulomata both of the orbit and of the nose and lungs.

A curious feature of granulomatous lesions in the face is that they tend to grow and spread through the destruction of adjacent regions, as is seen particularly clearly in our case. Here the granuloma extended through the inferior orbital fissure to the pterygopalatine fossa and through the superior orbital fissure into the extradural space of the left middle cranial fossa. Most remarkable, however, was the presence of granulomatous material on the inside of the dura and between the leptomeninges. This spread had, conceivably, proceeded very gradually (over a period of years) through a continuous expansion of the original lesion in the left orbit. In common with other authors (Williams, 1949; Godman and Churg, 1954; Budzilovich and Wilens, 1960), we believe that the destruction and spreading of the process are a result of an allergic reaction with successive breakdown of tissue at the interface between necrotized and vital cells.

In our case the clinical history shows that the local formation of granuloma preceded the manifestations of polyarteritis nodosa in the inner organs, which indicates that the generalized disease is secondary to the local process (cf. Walton and Leggat, 1956; Walton, 1958).

\section{EXPANSION OF ORBITAL AND NASAL GRANULOMATA INTRACRANIALLY}

Little attention has previously been paid to intracranial manifestations of the facial granulomata. Staehelin (1942) described the case of a 20-year-old girl who had had various ailments such as sore throat, and possibly signs of rheumatic fever, during a period of two years, and nasal obstruction and catarrh for eight months before admission. Subsequently, she developed fever, pains in the limbs and joints, and eventually, symptoms from the right eye. On admission, the nasal cavities were filled with purulent haemorrhagic crusts. She had pain around the right eye, and decreased vision, exophthalmos, lid swelling, impairment of movement, and decrease of pupillary responses on the right side. She died two weeks later after the disease had developed a fulminating febrile course. The necropsy showed a widespread vasculitis, glomerulonephritis, and numerous granulomatous lesions in the lungs, respiratory tract, kidneys, spleen, and small intestine. From our point of view, however, the most interesting feature was a granulomatous layer on the inside of the dura and around the optic fascicles. The author concluded that these masses emanated from the nasal cavity, and that penetration into the cranial cavity had been through the cribriform 
TABLE

COMPARISON OF FOUR SIMILAR CASES

\begin{tabular}{|c|c|c|c|c|}
\hline Author and Year & Sex & $\begin{array}{l}\text { Age at } \\
\text { Death }\end{array}$ & $\begin{array}{l}\text { Duration } \\
\text { of Disease }\end{array}$ & History and Findings \\
\hline \multirow[t]{2}{*}{ Hope-Robertson (1956) } & $\mathbf{M}$ & 38 & $5-7 \mathrm{yr}$. & $\begin{array}{l}\text { Rheumatic pains in hands and feet; unilateral pro- } \\
\text { ptosis, } 5 \text { yr. Biopsy, 'pseudo-tumour of the orbit'. } \\
\text { Eosinophilia in blood, albuminuria; shortly before } \\
\text { death pyrexia, purpuric rashes, haemoptysis. } \\
\text { Respiratory disease not mentioned. }\end{array}$ \\
\hline & & & & $\begin{array}{l}\text { Necropsy Hyaline-fibrous tissue with vasculitis in } \\
\text { orbit; glomerulitis and crescent formations; some tiny } \\
\text { vessels surrounded by polymorphs in heart; intra- } \\
\text { pulmonary haemorrhages but no necrotic or granu- } \\
\text { lomatous lesion. }\end{array}$ \\
\hline \multirow[t]{2}{*}{ Walton (1959) } & $\mathbf{M}$ & 53 & $5 \mathrm{mth}$ & $\begin{array}{l}\text { Unilateral proptosis } 4 \mathrm{mth} \text {. Death from peritonitis } \\
\text { following perforation of appendix. } \\
\text { Thick mucus in ethmoidal and sphenoidal air cells, } \\
\text { chronic non-specific granulomatous lesion in mucosa. } \\
\text { Operation, 'pseudo-tumour in posterior ethmoidal cells } \\
\text { penetrating superior and inferior orbital fissure,' } 3 \mathrm{mth} \text {. } \\
\text { before death. }\end{array}$ \\
\hline & & & & $\begin{array}{l}\text { Necropsy L. orbit, ethmoidal sinus, and both } \\
\text { sphenoidal air cells, non-specific chronic granuloma } \\
\text { with macrophages, plasma cells, lymphocytes, neutro- } \\
\text { phils, and eosinophils; infrequent giant cells of foreign } \\
\text { body type, no epithelioid cells; vessel walls normal. } \\
\text { Dura in anterior cranial fossa and over vertex diffusely } \\
\text { thickened; purulent pachymeningitis. In blood vessels } \\
\text { acute inflammation + fibrinoid necrosis and lesions } \\
\text { in different stages of healing with associated infarcts in } \\
\text { various organs. Fibrinoid changes in a few glomerular } \\
\text { capillaries. No vascular or granulomatous lesions in } \\
\text { lungs. }\end{array}$ \\
\hline
\end{tabular}

Faulds and Wear (1960) $\quad$ F $\quad 37 \quad 2$ yr. $\quad$ Unilateral proptosis 2 yr. Operation: solid mass in lower part of orbit extending back to apex of orbit. Non-specific granuloma with centres of plasma cells, polymorphs, one or two atypical giant cells. Purulent maxillary sinusitis same side as the affected eye at beginning of disease.

Necropsy Ulcerated lesion in L. orbit communicated with ethmoid sinus and extended into cranial cavity over interior surface of left frontal lobe. Large abscess cavity with pyogenic granulations, giant cells, and pink-stained protein deposits in lower lobe of R. lung. Arteritis in lungs, kidneys, and spleen. Glomerulitis, with primary infarction of capillary loops; wedge-shaped scars at surface.

Bilateral episcleritis $7 \mathrm{yr}$. before death, disappeared on R., remained on L. side. Pain L. eye and face, $5 \mathrm{yr}$. Rheumatic joint symptoms, signs of impaired renal function 4 yr. before death. Granulomatous lesion L. orbit discovered 1 yr. before death. Final episode of psychosis. Respiratory disease; period of infections in nose, sinuses, ear before eye symptoms appeared. Non-specific granulomatous process.

Necropsy Orbit filled with hyalin-fibrotic, partly fibrinoid-necrotic tissue with collections of round cells, single epithelioid and giant cells, and vasculitis. Granulation tissue extended through inferior orbital fissure to pterygopalative fossa and through superior orbital fissure to extradural space of middle cranial fossa, surrounding atrophic optic nerve, eye, muscle nerves, and branches of trigeminus. Similar granulation tissue over inside of dura and in subarachnoid. Ischaemic changes in cortex. Healed pericarditis; necrotizing vasculitis, fibrinoid necrosis, processes in different stages of healing, in kidneys and spleen; acute and subchronic glomerulonephritis: extensive destruction of glomeruli.
Authors' Diagnosis

Pseudo-tumour of the orbit + polyarteritis nodosa

Pseudo-tumour of the orbit $\overrightarrow{\vec{\sigma}}$ t polyarteritis nodosa

Pseudo-tumour of the orbit?

+ Wegener's granuloma

Chronic non-specific orbital granuloma with intracranial extension + polyarteritis nodosa. 
laminae. No mention was made of the orbits and sinuses. The leptomeninges and the brain were apparently unaffected. The striking similarities between this and our case have convinced us that the basic disease was the same. However, there were many differences which emphasize the wide range in course, symptoms, and organ involvement in this group of diseases.

Other reports have only briefly mentioned the intracranial manifestations of granulomata in the orbit and sinuses. Alexander (1954) described a case in which there was affection of 'the dura of the left frontal area', beside necrotizing lesions in the nose, paranasal sinuses, orbits, pharynx, trachea, bronchi, and lungs. Jackson (1958) found, when operating on a 25-year-old Greek woman, an orbital granuloma which tracked back through the sphenoidal fissure and involved the meninges of the middle fossa. Microscopic examination of the leptomeninges showed thickening through infiltration by round cells, plasma cells, polymorphs, and some endothelial cells. He suggested that strange types of granulomata were encountered, especially in patients from the Mediterranean area and the Middle East. In the case described by Walton (1959, see Table) an operation disclosed a mass in the posterior ethmoidal cells 'penetrating the superior and inferior orbital fissures to surround the optic nerves'. At necrospy the dura was found to be thickened in the anterior cranial fossa and over the vertex, but microscopical examination showed only acute pachymeningitis and recent arteritis. Faulds and Wear (1960, see Table) described a large ulcerated area in the left orbit which communicated with the ethmoid sinuses and extended into the cranial cavity over the inferior surface of the left frontal lobe.

As far as we know, intracranial spread has never been so extensive as in our case, and a unique feature was the presence of lesions in the subarachnoid space combined with affection of the cortex. This far-reaching diffusion of the disease was probably favoured by the slow course of the disease and the relatively mild involvement of internal organs.
This survey indicates certain patterns of intracranial manifestations. Thus, a nasal granulomatous process can spread to the adjacent sinuses and the orbits. From the ethmoid cells and sphenoid sinuses it can reach the floor of the anterior cranial fossa and grow around the optic chiasma and fascicles. An orbital granuloma can extend locally through the inferior orbital fissure to the pterygopalatine fossa or reach the middle cerebral fossa via the superior orbital fissure and along the dural sheath of the optic fascicles. After penetrating the dura the granulomatous process can spread along the inside of this membrane and eventually affect the leptomeninges.

We are indebted to Dr. Nils Ringertz, Professor of Pathology, for reading the manuscript, and to many colleagues in Stockholm for furnishing records and other information concerning this case.

\section{REFERENCES}

Ahlström, C. G., Liedholm, K., and Truedsson, E. (1953). Acta med. scand., 144, 323.

Alexander, F. W. (1954). Ann. Otol. (St. Louis), 63, 171.

Budzilovich, G. N., and Wilens, S. L. (1960). Arch. Path., 70, 653 Duke-Elder, S. (1952). Textbook of Ophthalmology, vol. 5. Kimpton, London.

Easton, J. A., and Smith, W. T. (1961). J. Path. Bact., 82, 345.

Faulds, J. S., and Wear, A. R. (1960). Lancet, 2, 955.

Flatmark, T. (1961). Nord. Med., 66, 1491.

Friedmann, I. (1955). J. Laryng., 69, 331.

Godman, G. C., and Churg, J. (1954). Arch. Path., 58, 533.

Hope-Robertson, W. J. (1956). Trans. ophthal. Soc. N. Z., 8, 56.

Howells, G. H. (1955). J. Laryng., 69, 309.

—, and Friedmann, I. (1950). J. clin. Path., 3, 220.

Hultberg, S., Koch, H., Moberger, G., and Mårtensson, G. (1957). Acta radiol. (Stockh.), 47, 229.

Jackson, H. (1958). Brit. J. Ophthal., 42, 212.

Paterson, W. (1956). Acta Oto-laryng. (Stockh.), 46, 43.

Reese, A. B. (1956). Atlas of Tumor Pathology, Fasc. 38: Tumors of the Eye and Adnexa. Armed Forces Institute of Pathology, Washington.

Ringertz, N. (1947). Nord. Med., 36, 2252.

Rose, G. A., and Spencer, H. (1957). Quart. J. Med., 26, 43.

Staehelin, H. R. (1942). Virchows Arch. path. Anat., 309, 235.

Stewart, J. P. (1933). J. Laryng., 48, 657.

Straatsma, B. R. (1957). Amer. J. Ophthal., 44, 789.

Stratton, H. J. M., Price, T. M. L., and Skelton, M. O. (1953). Brit. med. J., 1, 127.

Walton, E. W. (1958). Ibid., 2, 265.

(1959). J. clin. Path., 12, 419.

, and Leggat, P. O. (1956). Ibid., 9, 31.

Wegener, F. (1939). Beitr. path. Anat., 102, 36.

Weinberg, T. (1946). Amer. J. clin. Path., 16, 784.

Williams, H. L. (1949). Ann. Otol. (St. Louis), 58, 1013.

Woodburn, C. C. Jr., and Harris, H. E. (1951). Cleveland Clin. Quart., $18,165$. 